Supplement of The Cryosphere, 12, 3577-3588, 2018

https://doi.org/10.5194/tc-12-3577-2018-supplement

(c) Author(s) 2018. This work is distributed under

the Creative Commons Attribution 4.0 License.

(c) (1)

Supplement of

\title{
What historical landfast ice observations tell us about projected ice conditions in Arctic archipelagoes and marginal seas under anthropogenic forcing
}

Frédéric Laliberté et al.

Correspondence to: Frédéric Laliberté (laliberte.frederic@gmail.com)

The copyright of individual parts of the supplement might differ from the CC BY 4.0 License. 

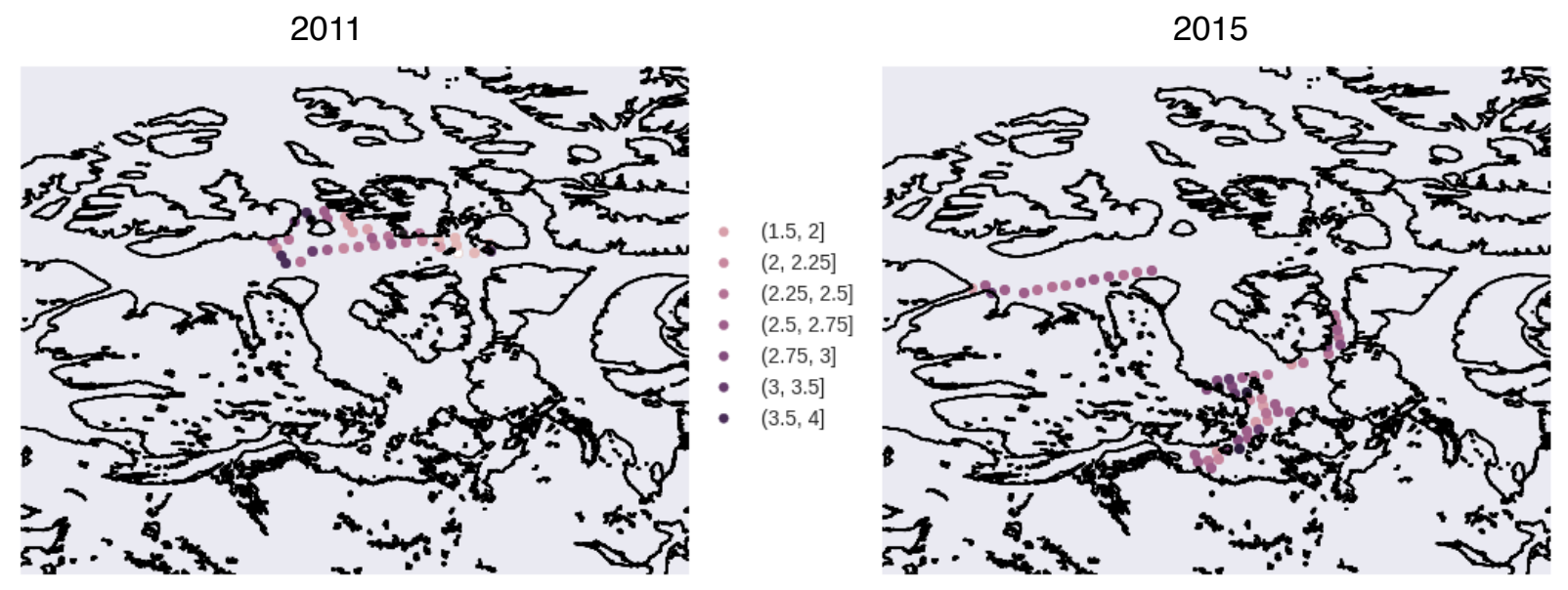

Figure S1. Airborne electromagnetic survey sea ice thickness in 2011 and 2015 averaged on a 25km EASE grid 2.0. 


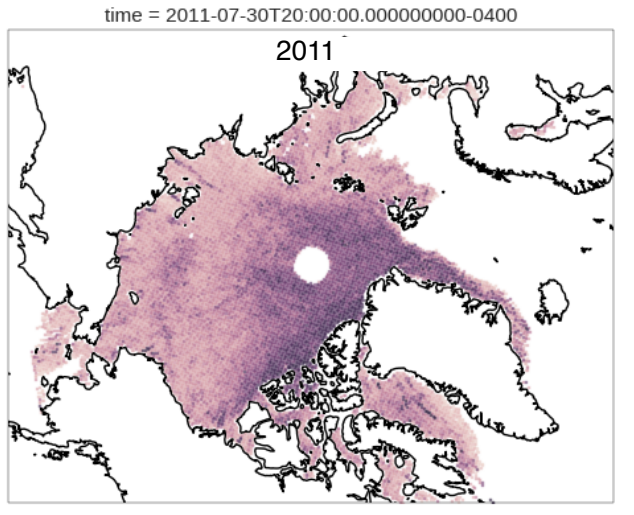

2013
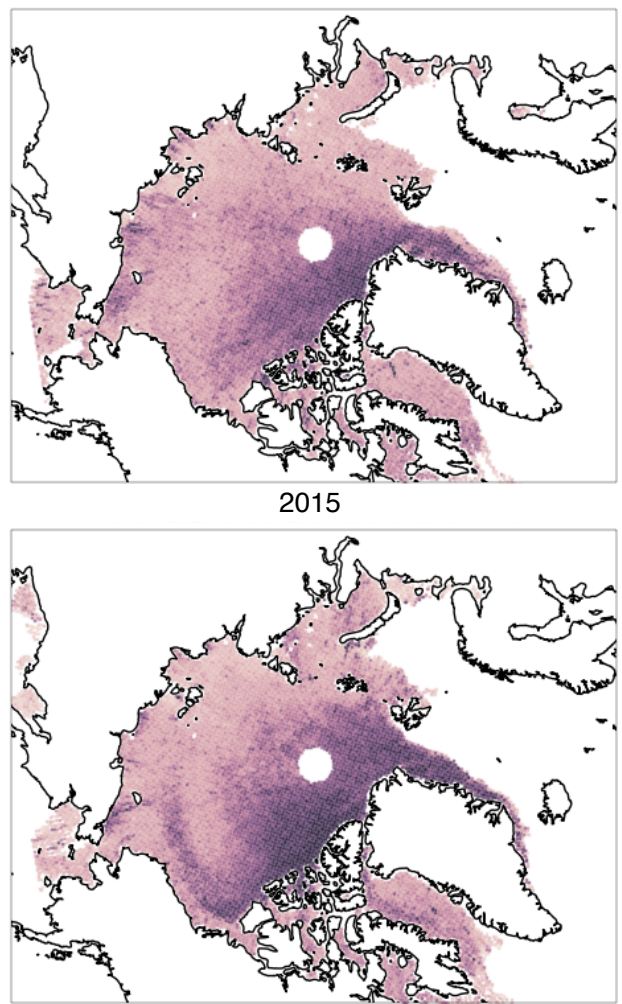

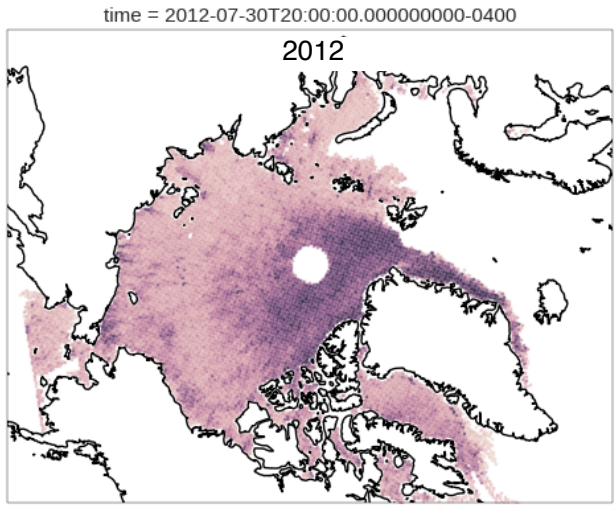

2014
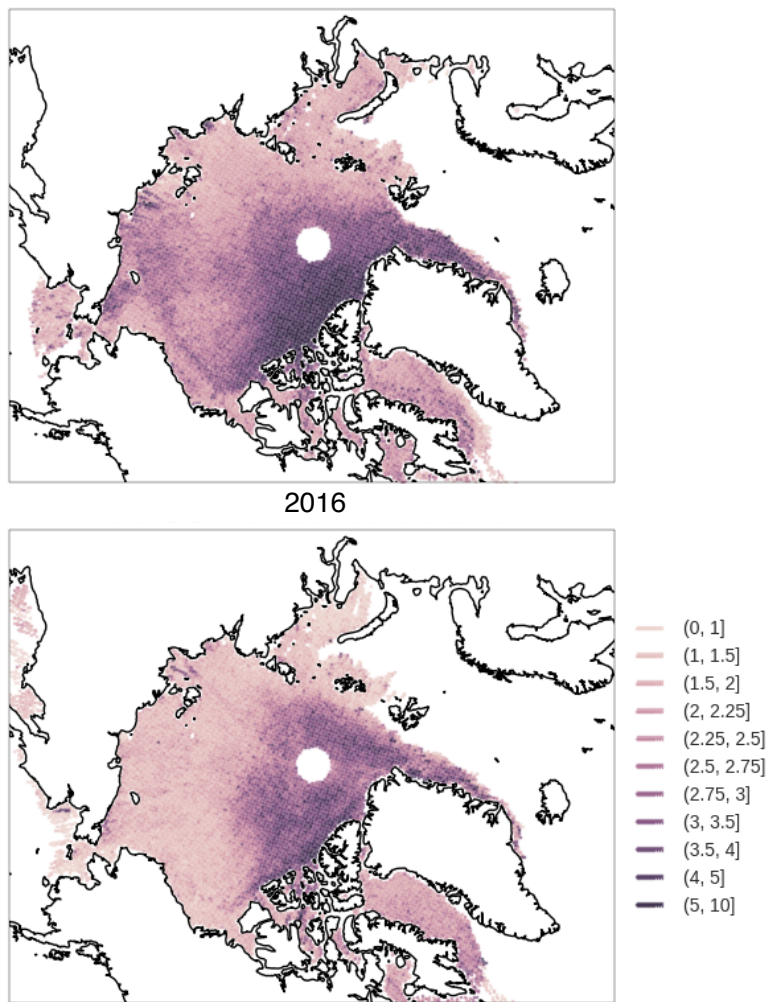

Figure S2. CryoSat2 annual maximum sea ice thickness from 2011 to 2016 on an EASE 2.0 grid. 